\title{
Building Resilience on Adolescent Mental Health Associated with Emerging Risk and Protective Factors among Ethnic Groups
}

\author{
Gizem Arat ${ }^{1}$ \\ ${ }^{1}$ Department of Social Work and Social Administration, The University of Hong Kong, Hong Kong \\ Correspondence: Gizem Arat, Department of Social Work and Social Administration, The University of Hong \\ Kong, Centennial Campus, The Jockey Club Tower, Hong Kong. Tel: 852-391-77-364. E-mail: \\ gizarat@gmail.com
}

Received: August 8, 2014

Accepted: September 8, $2014 \quad$ Online Published: October 15, 2014

doi:10.5539/jedp.v4n2p82

URL: http://dx.doi.org/10.5539/jedp.v4n2p82

\begin{abstract}
A bulk of studies have focused on systematically catalogued risk and protective factors (e.g., parental monitoring, peer, neighborhood support) in terms of adolescent mental health status concerning resilience; however, they did not display any improvement regarding adolescent mental health, particularly in school-based interventions. Therefore, I suggested that whether other emerging factors (e.g., nutrition, physical activity) could be beneficial to promote effective school-based interventions. Hence, I examined adolescent mental health outcomes (depression and suicidality) associated with dietary patterns, physical activity, social support, watching TV, video/computer games, and sleeping habits factors regarding resilience approach. A secondary data analysis was employed based on the 2011 national Youth Risk Behavior Survey (YRBS) among 15,364 12-18 year-old African American, Asian, and Caucasian adolescents. Regarding nutrition, low levels of fruit, vegetable, potato, and fruit juice were associated with higher odds of depression, suicidal ideation, suicide attempts, for the most part among diverse ethnicities. Similarly, greater green salad intake resulted in lower odds of poor mental health outcomes among Asians and Caucasians. Next, consistent with current literature, low levels of social support in schools and higher levels of joining a sport team were strong predictors of poor mental health outcomes among overall ethnic groups. Lastly, healthy sleeping patterns, greater physical activity, low levels of being bullied in school, cyber bullied, and video/computer games increased the risk of poor mental health outcomes among adolescents.
\end{abstract}

Keywords: adolescent, mental health, suicidality, resilience

\section{Introduction}

Adolescence is a vital transitional life stage between childhood and adulthood in which effective-school based interventions become salient (Theron, Liebenberg, \& Malindi, 2014) to improve adolescent mental health status. Thus, it is crucial to explore the possible risk and protective factors to develop programs and design interventions for the promotion of positive mental health in adolescence underpinning resilience since the symptoms of mental illnesses, in general, appear before 14 years of age (Jacka et al., 2013; Williams, Holmbeck, \& Greenley, 2002). Accordingly, the World Health Organization (WHO) recognizes the significance of better mental health outcomes of adolescents and targets to enhance the effectiveness of current interventions. Within this scope, an extensive research have investigated resilience regarding several catalogued and repeated factors such as parental monitoring (Li, Fang, Stanton, Su, \& Wu, 2003; Lipps et al., 2012), peer support (Wu, Palinkas, \& He, 2010), school (King, 2001), spirituality/religious beliefs (Hill \& Pargament, 2003), and neighborhood collectivity (Murry, Gaylord-Harden, Berkel, Copeland-Linder, \& Nation, 2011; Pettit, Bates, Dodge, \& Meece, 1999) associated with better adolescent mental health outcomes.

\subsection{Theoretical Framework}

The current study is heavily grounded in resilience approach. Resilience is a dynamic process (Rutter, 1985) in which existing protective and risk factors occur. Resilience is an on-going process in which an individual should bounce back and recover from disadvantaged situations or stress (Ungar, 2010), dominantly so-called as ordinary magic (Masten, 2001) focusing on strengths rather than deficits (Khanlou \& Wray, 2014) that empowers marginalized or more vulnerable social groups (Brodsky \& Cattaneo, 2013; Ungar, 2001). In essence, resilience 
should occur under two prominent conditions: (1) severe adversity or threat against one's well-being or health; and (2) recovery from stressful experiences resulting in positive psychology (Masten, Best, \& Garmezy, 1990; Werner \& Smith, 1982). Thus, it has been a popular concept particularly for youth positive development (Sharkey, You, \& Schnoebelen, 2008; Zimmerman, 2013) concerning vulnerable youth exposing to poor mental health outcomes such as depression, loneliness, anxiety, and suicidality with respect to family support, peer support, school climate, and neighborhood particularly among diverse cultures.

\subsection{Constructing New Risk and Protective Factors to Build Resilience}

On the one hand, there is convincing evidence that the dietary patterns of adolescents is one of the significant indicators of better mental health outcomes (Bakhtiyari, 2012; Estherlydia \& John, 2009; Lien, 2007; Lien, Heyerdahl, Thoresen, \& Bjertness, 2006; Oddy et al., 2009; Takaoka \& Kawakami, 2013; Weng et al., 2011) in which healthy eating habits decreased the risk of depression, anxiety, and suicidality. Hence, healthy dietary patterns are considered one of the modifiable protective factors (McMartin, Jacka, \& Colman, 2013) based on positive youth development and psychology. Likewise, the link between physical activity and mental health has been another controversial topic, especially with respect to anxiety and depression (Brosnahan, Steffen, Lytle, Patterson, \& Boostrom, 2004). Many studies suggested that greater physical activity helps adolescents decrease the likelihood of poor mental health outcomes (Biddle \& Asare, 2011; DeMoor, Boomsma, Stubbe, Willemsen, \& de Geus, 2008; Hallal, Victoria, Azevedo, \& Wells, 2006; Molt, Birnbaum, Kubik, \& Dishman, 2004; Ortega, Ruiz, Castillo, \& Sjostrom, 2008). Similar to nutrition and physical activity, healthy sleeping patterns decreased the risk of poor mental health outcomes (Sarchiapone et al., 2014) in peer-reviewed literature. Additionally, the relationship among cyber bullying and school bullying and adolescent mental health has been a trending concern in existing studies (Chang et al., 2013; Turner, Exum, Brame, \& Holt, 2013) and they found that these types of bullying had an negative impact on adolescent mental health. Lastly, regarding video/computer games, mixed findings were displayed. Granic, Lobel, and Engels (2013) suggest that such games may have some psychosocial benefits. Similarly especially the moderate levels of video/computer games can improve adolescent mental health (Allahverdipour, Bazargan, Farhadinasab, \& Moeini, 2010). On the other hand, it was found to elevate anxiety levels among adolescents (Dolatabadi, Eslami, Mostafavi, Hassanzade, \& Moradi, 2013; Mentzoni et al., 2011).

To sum up, fostering resilience can be prominent for enhanced adolescent mental health regarding their social factors (Ungar, 2012; Ungar, Russell, \& Connelly, 2014) such as peers, parents (Khanlou \& Wray, 2014; Masten, 2014) and along with external factors such as improved eating habits (Yousafzai, Rasheed, \& Bhutta, 2013) and physical activity (Hjemdal, Friborg, Stiles, Martinussen, \& Rosenvinge, 2006; Skrove, Romundsta, \& Indredavik, 2013; Strohle, 2009).

\subsection{The Present Study}

In general, most studies employ socio-ecological perspective (Ungar, 2012), especially in adolescence to consider resilience embedded in diverse socio-cultural contexts since it is context dependent (Luthar, Cicchetti, \& Becker, 2000) and needs more empirical studies from a multidimensional approach (Carbonell, Reinherz, \& Giaconia, 1998). Unfortunately, no study has examined resilience from a multidimensional approach (Khanlou \& Wray, 2014; Winders, 2014) merging untraditional variables such as school factors (e.g., school counselors) and external factors (e.g., sports) (Gore \& Aseltine, 1995) regarding socio-ecological perspective which can improve adolescent mental health targeting to promote effective school-based interventions. In conclusion, an updated multifaceted analysis is urgently needed in terms of fostering resilience which can improve adolescent mental health to capture the overall picture (Rutter, 1987, 2006; Windle, 2011) since current school-based interventions did not provide any effective designs regarding resilience (Hart \& Heaver, 2013) due to the consistently cataloguing similar factors such as parent, school, or peer. Therefore, I targeted to find possible risk and protective factors from a novel multidimensional approach consist of both school (being bullied in school, and social support) and external factors (video/computer games, watching TV, healthy eating habits, nutrition, physical activity, and being cyber bullied) in adolescence which may reduce poor mental health outcomes (depression, suicidal ideation, suicide attempts, and suicide plan), for the future design of school-based interventions.

In this study, I identified proposed protective factors as high levels of joining a sport team, high levels of carrot, green salad, and fruit juice consumption, low levels of carbonated soft drink intake, low levels of being bullied in school and being cyber bullied, low levels of watching TV, and video/computer games; and risk factors as low 
levels of physical activity, low levels of vegetable, fruit, carrot, and breakfast consumption, low levels of social support, and low levels of healthy sleeping habits.

\section{Methods}

\subsection{Participants}

The Youth Risk Behavior Surveillance System (YRBSS) was developed by the Centers for Disease Control and Prevention (2014) uses a national school-based survey design to assess self-reported students generally aged 12-18 years (grades 9 through 12) about health-risk behavior prevalence, trends over time, further evaluate and improve health-related policies and programs, including questions such as unhealthy dietary behaviors and mental health biennially. This study employed a secondary data analysis of the 2011 Youth Risk Behavior Survey (YRBS) (Centers for Disease Control and Prevention, 2011). For ethical approval, informed consent was received from students' parents. Students participation was voluntary, anonymous, and confidential. Furthermore, in this study, the sample size consisted of 15,364 school-going adolescents aged 12-18 years in national high schools in the 50 States and the District of Colombia in the year of 2011. More, the school response rate was $81 \%$ and overall response rate was $71 \%$, respectively.

\subsection{Variables}

School factors: Being bullied in school was measured with the established statements: ("During the past 12 months, have you ever been bullied on school property?") and social support ("During the past 12 months, did you talk to a teacher or other adult in your school about a personal problem you had?").

External factors: Video/computer games was assessed by ("On an average school day, how many hours do you play video or computer games or use a computer for something that is not school work?"), watching TV ("On an average school day, how many hours do you watch TV?"), healthy sleeping habits ("On an average school night, how many hours of sleep do you get?"). Further dietary patterns was assessed by eight questions: fruit juice consumption ("During the past 7 days, how many times did you drink $100 \%$ fruit juices such as orange juice, apple juice, or grape juice?"), fruit consumption (“During the past 7 days, how many times did you eat fruit?"), green salad consumption ("During the past 7 days, how many times did you eat green salad?"), potato intake ("During the past 7 days, how many times did you eat potatoes?" Do not count french fries, fried potatoes, or potato chips), carrot consumption ("During the past 7 days, how many times did you eat carrots?"), vegetable consumption ("During the past 7 days, how many times did you eat other vegetables?"), milk intake ("During the past 7 days, how many glasses of milk did you drink?"), and breakfast consumption ("During the past 7 days, on how many days did you eat breakfast?"). Next, physical activity was measured with ("During the past 7 days, on how many days were you physically active for a total of at least 60 minutes per day?"), cyber bullied ("During the past 12 months, have you ever been electronically bullied?"), and sports team ("During the past 12 months, on how many sports teams did you play? Count any teams run by your school or community groups.”). All variables were dichotomized based on yes/no.

\subsection{Data Analysis}

Data analysis was performed using SPSS software, version 17.0. A multiple imputation method was utilized for variables where the amount of missing data exceed 5 percent to overcome the weakness in analyzing, or preventing any bias, or misinterpretation, and to secure representativeness (Gelman \& Hill, 2006; Sterne et al., 2009).

\section{Results}

The prevalence of adolescent mental health outcomes and associations were shown in the current study (Table 1). Next, the resilience factors which displayed diverse patterns of associations with physical activity, being bullied in school, cyber being bullied, social support, consumption of vegetable, fruit, milk, breakfast, soft drink, video/computer games, and healthy sleeping habits for overall ethnicities based on mental health outcomes were displayed (Table 2).

\subsection{School Factors}

Low levels of physical activity resulted in lower odds of suicidal ideation among African-Americans and Caucasians, while it was associated with decreased likelihood of suicide plan among Caucasians, and suicide attempts among African-Americans and Caucasians. With respect to social support, low levels of social support had greater odds of depression, suicidal ideation, suicide plan, and suicide attempts among overall ethnicities. Moreover, low levels of healthy sleeping habits predicted decreased likelihood of depression among overall 
ethnic groups, and lower odds of suicidal ideation, suicide plan, and suicide attempts among African Americans and Caucasians.

\subsection{External Factors}

In terms of nutrition, lower levels of vegetable consumption were strongly related to increased likelihood of depression among Asians, African Americans, and Caucasians. However, it resulted in higher odds of suicide plan among African Americans and Caucasians, and it further was associated with increased likelihood of suicide attempts among African Americans and Caucasians. Next, low levels of fruit intake were strong predictors of depression among Caucasians. More, reduced breakfast consumption had lower odds of depression and suicidal ideation among overall ethnic groups, while it decreased the risk of suicide plan and suicide attempts among Caucasians. Additionally, low levels of milk intake were associated with higher odds of depression among Caucasians, suicidal ideation and suicide attempts among overall ethnic groups, and suicide plan among African Americans. Further, reduced likelihood of soft drink increased the odds of depression among Caucasians, decreased the odds of suicidal ideation among Asians and African Americans, and increased the odds of suicide plan and suicide attempts among overall ethnic groups. In addition to those, higher levels of carrot consumption resulted in greater odds of suicide attempts among African Americans. Greater green salad consumption resulted in lower odds of suicidal ideation among Asians and Caucasians. Moreover, higher levels of potato intake had lower odds of suicidal ideation among Asians, and it predicted lower odds of suicide plan among Caucasians. Greater fruit juice consumption resulted in lower odds of suicide plan among African Americans. Lastly, regarding joining sport team, video/computer games and watching TV, mixed findings were observed.

Table 1.The characteristics of participants

\begin{tabular}{llll}
\hline & \multicolumn{3}{c}{ Ethnicity } \\
\cline { 2 - 4 } & Asian & African American & Caucasian \\
& $M(\mathrm{SD})$ & $M(\mathrm{SD})$ & $M(\mathrm{SD})$ \\
\hline Age (years) & $1.8(.35)$ & $1.9(.30)$ & $1.9(.30)$ \\
& Percentage $\%$ & Percentage $\%$ & Percentage \% \\
Gender & & & \\
\multicolumn{1}{c}{$\quad$ Female } & 46.3 & 51.1 & 49.9 \\
$\quad$ Male & 57.3 & 48.9 & 50.1 \\
Physically active for 7 days & 16.7 & 24.7 & 28.2 \\
Vegetable consumption & 19.5 & 16.1 & 14.5 \\
Fruit consumption & 25.8 & 34.6 & 32.3 \\
Social support & 22.9 & 29.0 & 28.6 \\
Healthy sleeping habits & 22.1 & 27.2 & 32.7 \\
Breakfast consumption & 31.5 & 27.7 & 39.1 \\
Milk consumption & 8.5 & 9.1 & 15.2 \\
Joined sport team & 46.8 & 53.8 & 56.5 \\
Video/computer games & 39.5 & 38.1 & 30.1 \\
Watching TV & 32.9 & 53.7 & 28.5 \\
Carbonated soft drink consumption & 31.4 & 31.6 & 28.3 \\
Carrot consumption & 50.7 & 34.0 & 50.8 \\
Potato consumption & 59.7 & 56.7 & 71.6 \\
Green salad consumption & 60.7 & 53.5 & 63.2 \\
Fruit juice consumption & 86.9 & 82.5 & 89.1 \\
\hline
\end{tabular}




\begin{tabular}{llll}
\hline Being bullied in school & 15.8 & 10.5 & 20.5 \\
Cyber bullied & 14.5 & 9.4 & 16.6 \\
\hline
\end{tabular}

$* \mathrm{p}<.0 .5, * * \mathrm{p}<.001$

Note. $\mathrm{CI}=$ confidence; $\mathrm{LL}=$ lower limit, $\mathrm{UL}=$ upper limit.

Table 2. Binary logistic regression analysis on adolescent mental health predictors

\begin{tabular}{|c|c|c|c|}
\hline \multirow{3}{*}{ Ethnicity } & \multicolumn{3}{|c|}{ Depression } \\
\hline & Asian & African American & Caucasian \\
\hline & 95\% CI (LL, UL) & 95\% CI (LL, UL) & $95 \%$ CI (LL, UL) \\
\hline Physically active for 7 days & $1.05(.71,1.55)$ & $.85(.72,1.01)$ & $.63(.57, .71)^{* *}$ \\
\hline Vegetable consumption & $1.67(1.16,2.38)^{*}$ & $1.41(1.17,1.71)^{* *}$ & $1.28(1.12,1.45)^{* *}$ \\
\hline Fruit consumption & $1.01(.71,1.44)$ & $1.09(.93,1.28)$ & $1.16(1.04,1.29)^{*}$ \\
\hline Breakfast consumption & $.65(.46, .92)^{*}$ & $.70(.59, .84)^{* *}$ & $.69(.62, .76)^{* *}$ \\
\hline Milk consumption & $1.08(.61,1.90)$ & $1.32(1.03,1.70)^{*}$ & $1.17(1.02,1.34)^{*}$ \\
\hline Carbonated soft drink consumption & $.81(.58,1.13)$ & $.91(.78,1.05)$ & $1.11(1.01,1.23)^{*}$ \\
\hline Carrot consumption & $1.10(.79,1.53)$ & $1.09(.91,1.30)$ & $1.10(.97,1.24)$ \\
\hline Potato consumption & $.34(.13, .91)^{*}$ & $.83(.48,1.44)$ & $.76(.53,1.10)$ \\
\hline Green salad consumption & $1.83(.57,5.84)$ & $.67(.40,1.13)$ & $.76(.49,1.17)$ \\
\hline Fruit juice consumption & $1.15(.50,2.61)$ & $.79(.58,1.07)$ & $.84(.65,1.07)$ \\
\hline Social support & $2.27(1.62,3.19)^{* *}$ & $2.00(1.72,2.32)^{* *}$ & $2.29(2.08,2.52)^{* *}$ \\
\hline Healthy sleeping habits & $.59(.40, .88)^{*}$ & $.65(.55, .78)^{* *}$ & $.53(.48, .60)^{* *}$ \\
\hline Joined sport team & $.70(.51, .97)^{*}$ & $.82(.70, .95)^{*}$ & $.69(.62, .76)^{* *}$ \\
\hline Video/computer games & $.78(.56,1.09)$ & $.85(.73, .98)^{*}$ & $.61(.55, .67)^{* *}$ \\
\hline Watching TV & $1.10(.81,1.48)$ & $1.10(.95,1.28)$ & $.98(.90,1.08)$ \\
\hline Being bullied in school & $3.20(2.39,4.29)^{* *}$ & $3.39(2.69,4.27)^{* *}$ & $2.80(2.51,3.13)^{* *}$ \\
\hline \multirow[t]{2}{*}{ Cyber bullied } & $5.41(3.34,8.76)^{* *}$ & $3.19(2.46,4.13)^{* *}$ & $3.18(2.79,3.63)^{* *}$ \\
\hline & \multicolumn{3}{|c|}{ Suicidal ideation } \\
\hline \multirow[t]{2}{*}{ Ethnicity } & Asian & African American & Caucasian \\
\hline & 95\% CI (LL, UL) & 95\% CI (LL, UL) & $95 \%$ CI (LL, UL) \\
\hline Physically active for & $1.55(1.00,2.42)$ & $.79(.64, .99)^{*}$ & $.68(.60, .79)^{* *}$ \\
\hline \multicolumn{4}{|l|}{7 days } \\
\hline Vegetable consumption & $.74(.48,1.14)$ & $.82(.66,1.02)$ & $.92(.81,1.05)$ \\
\hline Fruit consumption & $1.08(.71,1.64)$ & $1.10(.91,1.33)$ & $1.10(.971,24)$ \\
\hline Breakfast consumption & $.48(.30, .75)^{*}$ & $.78(.62, .97)^{*}$ & $.66(.57, .75)^{* *}$ \\
\hline Milk consumption & $2.75(1.52,4.98)^{*}$ & $1.71(1.27,2.29)^{* *}$ & $1.26(1.07,1.49)^{*}$ \\
\hline Carbonated soft & $.27(.10, .71)^{*}$ & $.53(.35, .78)^{*}$ & $.46(.36, .60) 8$ \\
\hline \multicolumn{4}{|l|}{ drink consumption } \\
\hline Carrot consumption & $.59(.17,2.00)$ & $.59(.30,1.17)$ & $.86(.53,1.41)$ \\
\hline Potato consumption & $.50(.18,1.39)$ & $.90(.46,1.75)$ & $.82(.52,1.27)$ \\
\hline Green salad consumption & $.35(.18, .66)^{*}$ & $.42(.12,1.43)$ & $.41(.25, .66)^{* *}$ \\
\hline Fruit juice consumption & $1.53(.58,4.06)$ & $1.03(.70,1.50)$ & $1.27(.92,1.76)$ \\
\hline
\end{tabular}




\begin{tabular}{|c|c|c|c|}
\hline Social support & $2.01(1.36,2.97)^{* *}$ & $1.56(1.29,1.88)^{* *}$ & $1.81(1.60,2.04)^{* *}$ \\
\hline Healthy sleeping habits & $.61(.37,1.00)$ & $.65(.52, .82)^{* *}$ & $.60(.52, .69)^{* *}$ \\
\hline Joined sport team & $1.07(.73,1.56)$ & $.82(.68,1.00)$ & $.75(.66, .85)^{* *}$ \\
\hline Video/computer games & $.58(.29,1.16)$ & $.94(.67, .13)$ & $.53(.42, .67)^{* *}$ \\
\hline Watching TV & $1.58(.86,2.93)$ & $.43(.22, .84)^{*}$ & $.87(.65,1.15)$ \\
\hline Being bullied in school & $2.22(1.39,3.56)^{*}$ & $3.36(2.60,4.33)^{* *}$ & $3.35(2.94,3.81)^{* *}$ \\
\hline Cyber bullied & $2.19(1.58,3.03)^{* *}$ & $3.64(2.76,4.81)^{* *}$ & $2.70(2.32,3.14)^{* *}$ \\
\hline \multirow{3}{*}{ Ethnicity } & \multicolumn{3}{|c|}{ Suicide plan } \\
\hline & Asian & African American & Caucasian \\
\hline & 95\% CI (LL, UL) & 95\% CI (LL, UL) & $95 \%$ CI (LL, UL) \\
\hline Physically active for 7 days & $1.40(.90,2.19)$ & $.83(.66,1.04)$ & $.74(.64, .85)^{* *}$ \\
\hline Vegetable consumption & $1.47(.96,2.23)$ & $1.44(1.13,1.83)^{*}$ & $1.43(1.21,1.69)^{* *}$ \\
\hline Fruit consumption & $.96(.62,1.47)$ & $1.11(.90,1.37)$ & $.98(.85,1.14)$ \\
\hline Breakfast consumption & $.69(.46,1.05)$ & $.85(.67,1.07)$ & $.67(.59, .78)^{* *}$ \\
\hline Milk consumption & $1.61(.87,2.97)$ & $1.43(1.04,1.96)^{*}$ & $1.31(1.10,1.56)^{*}$ \\
\hline Carbonated soft drink consumption & $2.03(1.39,2.96)^{* *}$ & $1.36(1.11,1.66)^{*}$ & $1.30(1.14,1.49)^{* *}$ \\
\hline Carrot consumption & $1.04(.72,1.49)$ & $1.10(.90,1.34)$ & $.89(.78,1.00)$ \\
\hline Potato consumption & $.99(.68,1.45)$ & $1.00(.82,1.22)$ & $.83(.72, .96)^{*}$ \\
\hline Green salad consumption & $.89(.59,1.33)$ & $.97(.79,1.19)$ & $.96(.83,1.09)$ \\
\hline Fruit juice consumption & $.96(.65,1.41)$ & $.75(.60, .94)^{*}$ & $1.00(.85,1.18)$ \\
\hline Social support & $2.24(1.53,3.30)^{* *}$ & $1.49(1.22,1.82)^{* *}$ & $1.79(1.57,2.03)^{* *}$ \\
\hline Healthy sleeping habits & $.72(.45,1.15)$ & $.64(.50, .81)^{* *}$ & $.66(.57, .76)^{* *}$ \\
\hline Joined sport team & $.92(.63,1.33)$ & $.71(.58, .86)^{*}$ & $.72(.63, .82)^{* *}$ \\
\hline Computer games & $1.62(1.13,2.32)^{*}$ & $1.17(.96,1.42)$ & $1.65(1.45,1.88)^{* *}$ \\
\hline Watching TV & $1.12(.77,1.63)$ & $1.06(.87,1.29)$ & $1.06(.92,1.21)$ \\
\hline Being bullied in school & $3.71(2.43,5.67)^{* *}$ & $3.37(2.65,4.28)^{* *}$ & $3.07(2.68,3.50)^{* *}$ \\
\hline \multirow[t]{2}{*}{ Cyber bullied } & $3.71(2.43,5.67)^{* *}$ & $3.37(2.65,4.28)^{* *}$ & $3.07(2.68,3.50)^{* *}$ \\
\hline & \multicolumn{3}{|c|}{ Suicide attempts } \\
\hline \multirow[t]{2}{*}{ Ethnicity } & Asian & African American & Caucasian \\
\hline & $95 \%$ CI (LL, UL) & 95\% CI (LL, UL) & $95 \%$ CI (LL, UL) \\
\hline Physically active for 7 days & $.98(.56,1.70)$ & $.72(.55, .95)^{*}$ & $.80(.66, .96)^{*}$ \\
\hline Vegetable consumption & $1.38(.85,2.25)$ & $1.54(1.18,2.02)^{*}$ & $1.77(1.45,2.16)^{* *}$ \\
\hline Fruit consumption & $.65(.38,1.12)$ & $1.24(.98,1.58)$ & $1.11(.92,1.33)$ \\
\hline Breakfast consumption & $.70(.43,1.15)$ & $.90(.69,1.16)$ & $.63(.53, .76)^{*}$ \\
\hline Milk consumption & $3.13(1.63,6.00)^{*}$ & $2.02(1.46,2.81)^{* *}$ & $1.52(1.24,1.88)^{* *}$ \\
\hline Carbonated soft drink consumption & $3.52(2.28,5.45)^{* *}$ & $1.68(1.34,2.10)^{* *}$ & $1.63(1.38,1.93)^{* *}$ \\
\hline Carrot consumption & $1.00(.65,1.53)$ & $1.46(1.17,1.82)^{*}$ & $1.10(.94,1.29)$ \\
\hline Potato consumption & $.84(.54,1.31)$ & $.90(.72,1.12)$ & $.88(.74,1.05)$ \\
\hline Green salad consumption & $.90(.55,1.45)$ & $.93(.73,1.17)$ & $1.15(.97,1.38)$ \\
\hline Fruit juice consumption & $.89(.57,1.40)$ & $.99(.76,1.30)$ & $1.07(.86,1.32)$ \\
\hline Social support & $2.27(1.46,3.51)^{* *}$ & $1.49(1.19,1.86)^{* *}$ & $1.77(1.51,2.09)^{* *}$ \\
\hline
\end{tabular}




\begin{tabular}{llll}
\hline Healthy sleeping habits & $.83(.48,1.42)$ & $.55(.41, .73)^{* *}$ & $.69(.57, .83)^{* *}$ \\
Joined sport team & $.89(.57,1.36)$ & $.80(.64,1.00)$ & $.68(.57, .80)^{* *}$ \\
Computer games & $1.52(1.00,2.30)$ & $1.31(1.06,1.63)^{*}$ & $1.50(1.27,1.77)^{* *}$ \\
Watching TV & $1.56(1.02,2.38)^{*}$ & $.98(.79,1.22)$ & $1.15(.97,1.37)$ \\
Being bullied in school & $3.78(2.31,6.16)^{* *}$ & $2.76(2.10,3.62)^{* *}$ & $2.99(2.54,3.54)^{* *}$ \\
Cyber bullied & $1.92(1.12,3.30)^{*}$ & $3.46(2.58,4.63)^{* *}$ & $3.02(2.49,3.65)^{* *}$ \\
\hline
\end{tabular}

\section{Discussion}

In this study, I sought to examine possible under-recognized multifaceted risk and protective factors which may enlighten mental health professionals and school staff to design effective school-based interventions building resilience among vulnerable diverse ethnic population. As I recall, there should be two conditions to specify resilience. First, both protective and risk factors should exist and have an adverse impact on adolescent development. Secondly, adolescents should overcome these and function healthy, in other terms, they should bounce back. Indeed, in my study, the participants' development and mental health status are assumed to be at risk. Finally, to foster resilience approach, it was proposed that low levels of physical activity, low levels of vegetable, fruit, carrot, and breakfast consumption, low levels of social support, low levels of healthy sleeping habits will more likely to increase their likelihood of depression, suicidal ideation, suicide plan, and suicide attempts. In addition, I hypothesized that high levels of joining a sport team, high levels of carrot, green salad, and fruit juice consumption, low levels of carbonated soft drink intake, low levels of being bullied in school and cyber being bullied, low levels of watching TV, and video/computer games will more likely to decrease poor mental health outcomes among school-going adolescents. I discussed the study findings as follows:

In terms of nutrition, mixed results were observed. Consistent with current literature, healthy dietary consumption in terms of lower levels of fruit, vegetable, fruit juice, and potato intake, and high levels of green salad consumption, had greater odds of poor mental health regarding depression, suicidal ideation, suicide attempts, and suicide plan, for the most part of Asians, Caucasians, and African Americans (Oddy et al., 2009; Weng et al., 2011). However, unexpectedly, mixed findings were displayed regarding greater carbonated soft drink and milk consumption. Both low levels of greater soft drink and milk resulted in lower odds of suicidal ideation among only Asians and African Americans respectively. One of the possible reasons of this relationship could be unique cultural dietary patterns. Nonetheless, as expected, they were associated with higher odds of depression, suicide plan and suicide attempts, for the most part among overall ethnicities which is similar to past study findings (Estherlydia \& John, 2009; Lien et al., 2006; Pan, Zhang, \& Shi, 2011). Moreover, low levels of breakfast intake decreased the risk of poor mental health outcomes among diverse ethnicities which contradicts with previous studies (O'Sullivan et al., 2009; Oellingrath, Svendsen, \& Hestetun, 2013). This result could be due to irregular breakfast consumption (Oellingrath et al., 2013). Finally, high levels of carrot intake resulted in increased likelihood of suicide attempts in Caucasians. The reason cannot be ruled out but it may be due to other unobserved factors such as history of sexual abuse or substance abuse.

In relation to physical activity, exercising on regular basis was associated with lower levels of poor mental health outcomes (Mangerud, Bjerkeset, Lydersen, \& Indredavik, 2014; Moljord, Moksnes, Espnes, Hjemdal, \& Eriksen, 2014) which is concordant with current study findings such as decreased risk of depression, anxiety, depression, suicide attempts, and suicidal ideation. Unexpectedly, in this study, both boys and girls were physically active as teenagers even though a systematic review of existing studies depicts the vice versa (Dumith, Gigante, Domingues, \& Kohl, 2011) due to possible low socioeconomic status (SES) (Stalsberg \& Pedersen, 2010). However, higher levels of exercising for 60 minutes were associated with higher odds of suicide plan for both genders in this study. This result cannot be ruled out; therefore, it may be due to diverse socio-cultural context (Richards, Foster, Townsend, \& Bauman, 2014).

Regarding social support, as expected, low levels of social support in school had greater odds of depression, suicidal ideation, suicide plan, and suicide attempts among Asians, Caucasians, and African Americans in this study. Although ethnic adolescent groups in the current study have relatively distinct cultural contexts, such as African Americas tend to employ more collectivistic traits than Caucasians, social support is still seen as a prominent marker for enhanced mental health among adolescents. This result is similar to the current literature suggesting that such as teachers, school counselors (Rak \& Patterson, 1996; Walsh, 2002) that can be role 
models and guiders to influence them positively. Next, low levels healthy sleeping patterns were associated with lower odds of poor mental health outcomes for the most part for diverse ethnicities which is dissimilar to the results of prior studies (Kaneita et al., 2007; Sarchiapone et al., 2014). This could be a result of unobserved factors such as individual factors and biological needs. Moreover, unexpectedly, low levels of cyber bullying and school bullying resulted in increased likelihood of poor mental health outcomes across diverse ethnicities which contradict previous findings (Bannink, Broeren, van de Looji-Jansen, de Waart, \& Raat, 2014). This could be other unobserved factors such as strong family bond or peer support. In terms of joining a sport team, high levels of joining a sport team decreased the risk of poor mental health among Caucasians and Asians which is similar to previous study findings (Rak \& Patterson, 1996); however; reduced sport team had lower odds of depression among Asians. This could be a result of cultural differences in which Asian adolescents may tend to exercise alone instead of joining group sports.

In this study, low levels of video/computer games resulted in decreased odds of depression and suicidal ideation among African Americans and Caucasians and solely Caucasians, respectively. However it was associated with higher odds of suicide plan and suicide attempts among Asians and Caucasians, and African Americans and Caucasians, respectively which is similar to existing findings (Zamani, Chashmi, \& Hedayati, 2009). Lastly, concerning watching TV, high levels of watching TV decreased the risk of suicidal ideation among African Americans, while low levels of watching TV increased the risk of suicide attempts among Asians which contradicts with prior studies (Primack, Swanier, Georgiopoulos, Land, \& Fine, 2009) may be due to family rituals.

This study confirms that adolescent mental health should be studied in terms of multilevel analysis from school and external factors to build and foster resilience which will be beneficial for public health practitioners and health educators to enhance positive mental health in adolescence. While considering these implications, the emerging risk and protective factors embedded in socio-cultural contexts should also be studied regarding resilience (Galambas \& Costigan, 2003; Ungar et al., 2014). To carry out this, not only teacher but also school nurses and psychologists should be included in cultural-sensitive programs and interventions to boost school-going adolescent mental health outcomes (Hunter, 2001). In conclusion, the application of resilience in preventative interventions is cost-effective for school-based interventions (Patterson, 2002) which may be useful for diverse ethnic groups to improve their mental health status.

\section{Limitations}

Several limitations should be noted in this study. First, these data were self-reported which limit inference of causation. Next, other ethnic groups were not included in this study due to the small number which effects adversely power of this study. Moreover, once-only school-based data analysis of three ethnic groups is insufficient to unpack the relationship between mental health associated factors; therefore, a follow-up longitudinal study is needed to identify other possible risk and protective factors to track resilience among school-going adolescents.

\section{Acknowledgement}

The opinions expressed by author contributing to this article do not necessarily reflect the opinions of the Centers for Disease Control and Prevention, or the author's affiliated institutions.

\section{References}

Allahverdipour, H., Bazargan, M., Farhadinasab, A., \& Moeini, B. (2010). Correlates of video games playing among adolescents in an Islamic country. BMC Public Health, 10(286). http://dx.doi.org/10.1186/1471-2458-10-286

Bakhtiyari, M. (2012). Fast-food consumption, micronutrient intake and anxiety levels among pupils aged 8-12 years old in Tehran-Iran. Archives of Disease in Childhood, 97. http://dx.doi.org/10.1136/archdischild-2012-302724.1427

Bannink, R., Broeren, S., van de Looji-Jansen, P. M., de Waart, F. G., \& Raat, H. (2014). Cyber and traditional bullying victimization as a risk factor for mental health problems and suicidal ideation in adolescents. Plos One, 9(4). http://dx.doi.org/10.1371/journal.pone.0094026

Biddle, S. J., \& Asare, M. (2011). Physical activity and mental health in children and adolescents: A review of

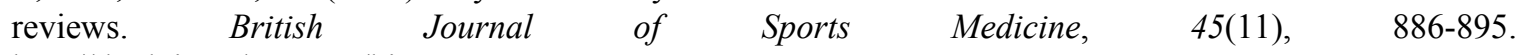
http://dx.doi.org/10.1136/bjsports-2011-090185 
Brodsky, A. E., \& Cattaneo, L. B. (2013). A transconceptual model of empowerment and resilience: Divergence, convergence and interactions in kindred community concepts. American Journal of Community Psychology, 52, 333-346. http://dx.doi.org/10.1007/s10464-013-9599-x

Brosnahan, J., Steffen, L. M., Lytle, L., Patterson, J. M., \& Boostrom, A. (2004). The relation between physical activity and mental health among Hispanic and Non-Hispanic White adolescents. Archives of Pediatrics \& Adolescent Medicine, 158, 818-823.

Carbonell, D. M., Reinherz, H. Z., \& Giaconia, R. M. (1998). Risk and resilience in late adolescence. Child and Adolescent Social Work Journal, 15, 251-272.

Centers for Disease Control and Prevention. (2011). Youth Risk Behavior Survey. Retreieved from http://www.cdc.gov/healthyouth/yrbs/index.htm

Chang, F.-C., Lee, C.-M., Chiu, C.-H., Hsi, W.-Y., Huang, T.-F., \& Pan, Y.-C. (2013). Relationships among cyberbullying, school bullying, and mental health in Taiwanese adolescents. Journal of School Health, 83(6), 454-462. http://dx.doi.org/10.1111/josh.12050

DeMoor, M. H., Boomsma, D. I., Stubbe, J. H., Willemsen, G., \& de Geus, E. J. (2008). Testing causality in the association between regular exercise and symptoms of anxiety and depression. Archives of General Psychiatry, 65(8), 897-905. http://dx.doi.org/10.1001/archpsyc.65.8.897

Dolatabadi, N. K., Eslami, A. A., Mostafavi, F., Hassanzade, A., \& Moradi, A. (2013). The relationship between computer games and quality of life in adolescents. Journal of Education and Health Promotion, 2(20), 1-5. http://dx.doi.org/10.4103/2277-9531.112691

Dumith, S. C., Gigante, D. P., Domingues, M. R., \& Kohl, H. W. r. (2011). Physical activity change during adolescence: A systematic review and a pooled analysis. International Journal of Epidemiology, 40, 685-698. http://dx.doi.org/10.1093/ije/dyq272

Estherlydia, D., \& John, S. (2009). Soft drink consumption and mental health outcomes among boys and girls in the age group of 17-23 years. Indian Journal of Nutrition Diet, 46, 278-289.

Galambas, N. L., \& Costigan, C. L. (2003). Emotional and personality development in adolescents. Handbook of Psychology, 6, 352-372. http://dx.doi.org/10.1002/0471264385.wei0614

Gelman, A., \& Hill, J. (2006). Data analysis using regression and multilevel/hierarchical models. UK: Cambridge University Press.

Gore, S., \& Aseltine, R. H. (1995). Protective processes in adolescence: Matching stressors with social resources. American Journal of Community Psychology, 23, 301-327.

Granic, I., Lobel, A., \& Engels, R. C. M. E. (2013). The benefist of playing video games. American Psychologist, 69(1), 66-78. http://dx.doi.org/10.1037/a0034857

Hallal, P. C., Victoria, C. G., Azevedo, M. R., \& Wells, J. C. (2006). Adoelscent physical activity and health: A systemic review. Sports Medicine, 36(12), 1019-1030.

Hart, A., \& Heaver, B. (2013). Evaluating resilience-based programs for schools using a systematic consultative review. Journal of Child and Youth Development, 1(1), 27-53.

Hill, P. C., \& Pargament, K. I. (2003). Advances in the conceptualization and measurement of religion and spirituality: Implications for physical and mental health research. American Psychologist, 58, 64-74.

Hjemdal, O., Friborg, O., Stiles, T., Martinussen, M., \& Rosenvinge, J. H. (2006). A new scale for adolescent resilience: Grasping the central protective resources behind healthy development. Measuring and Evaluation in Counseling and Development, 39, 84-96.

Hunter, A. J. (2001). A cross-cultural comparison of resilience in adolescents. Journal of Pediatric Nursing, 16(3), 172-179.

Jacka, F. N., Ystorm, E., Brantsaeter, A. L., Karevold, E., Roth, C., Haugen, M., ... Berk, M. (2013). Maternal and early postnatal nutrition and mental health of offspring by age 5 years: A prospective cohort study. Journal of American Academic Child and Adolescent Psychiatry, 52(10), 1038-1047.

Kaneita, Y., Ohida, T., Osaki, Y., Tanihata, T., Minowa, M., Suzuki, K., ... Havashi, K. (2007). Association between mental health status and sleep status among adolescents in Japan: a nationwide cross-sectional survey. Journal of Clinical Psychiatry, 68(9), 1426-1435. 
Khanlou, N., \& Wray, R. (2014). A whole community approach toward child and youth resilience promotion: A review of resilience literature. International Journal of Mental Health and Addiction, 12, 64-79. http://dx.doi.org/10.1007/s11469-013-9470-1

King, K. A. (2001). Developing a comprehensive school suicide prevention program. Journal of School Health, 71(4), 132-137.

Li, X., Fang, X., Stanton, B., Su, L., \& Wu, Y. (2003). Parental monitoring among adolescents in Beijing, China. Journal of Adolescent Health, 33, 130-132.

Lien, L. (2007). Is breakfast consumption related to mental distress and academic performance in adolescents? Public Health Nutrition, 10, 422-428.

Lien, L., Lien, N., Heyerdahl, S., Thoresen, M., \& Bjertness, E. (2006). Consumption of soft drinks and hyperactivity, mental distress, and conduct problems among adolescents in Oslo, Norwa. American Journal of Public Health, 96(10), 1815-1820. http://dx.doi.org/10.2105/ AJPH.2004.059477

Lipps, G., Lowe, G. A., Gibson, R. C., Halliday, S., Morris, A., Clarke, N., \& Wilson, R. N. (2012). Parenting and depressive symptoms among adolescents in four Caribbean societies. Child and Adolescent Psychiatry and Mental Health, 31(6). http://dx.doi.org/10.1186/1753-2000-6-31

Luthar, S. S., Cicchetti, D., \& Becker, B. (2000). The construct of resilience: A critical evaluation and guidelines for future work. Child Development, 71(3), 543-562.

Mangerud, W. L., Bjerkeset, O., Lydersen, S., \& Indredavik, M. S. (2014). Physical activity in adolescents with psychiatric disorders and in the general population. Child and Adolescent Psychiatry and Mental Health, $8(2), 1-10$. http://dx.doi.org/10.1186/1753-2000-8-2

Masten, A. (2014). Global perspectives on resilience in children and youth. Child Development, 85(1), 6-20. http://dx.doi.org/10.1111/cdev.12205

Masten, A., Best, K., \& Garmezy, N. (1990). Resilience and development: Contributions from the study of children who overcome adversity. Developmental Psychology, 2, 425-444.

Masten, A. S. (2001). Ordinary magic. Resilience processes in development. American Psychologist, 56(3), 227-238. http://dx.doi.org/10.1037//0003-066X.56.3.227

McMartin, S. E., Jacka, F. N., \& Colman, I. (2013). The association between fruit and vegetable consumption and mental health disorders: Evidence from five waves of a national survey of Canadians. Preventive Medicine, 56, 225-230. http://dx.doi.org/10.1016/j.ypmed.2012.12.016

Mentzoni, R. A., Brunborg, G. S., Molde, H., Myrseth, H., Skouverøe, K. J. M., Hetland, J., \& Pallesen, S. (2011). Problematic video game use: Estimated prevalence and associations with mental and physical health. Cyberpsychology, Behavior, and Social Networking, 14(10), 591-596.

Moljord, I. E. O., Moksnes, U. K., Espnes, G. A., Hjemdal, O., \& Eriksen, L. (2014). Physical activity, resilience, and depressive symptoms in adolescence. Mental Health and Physical Activity, 7, 79-85. http://dx.doi.org/10.1016/j.mhpa.2014.04.001

Molt, R. W., Birnbaum, A. S., Kubik, M. Y., \& Dishman, R. K. (2004). Naturally occurring changes in physical activity are inversely related to depressive symptoms during early adolescence. Psychosomatic Medicine, 66(3), 336-342.

Murry, V. M., Gaylord-Harden, N. K., Berkel, C., Copeland-Linder, N., \& Nation, M. (2011). Neighborhood poverty and adolescent development. Journal of Research on Adolescence, 21(1), 114-128. http://dx.doi.org/10.1111/j.1532-7795.2010.00718.x

O’Sullivan, T. A., Robinson, M., Kendall, G. E., Miller, M., Jacoby, P., Silburn, S. R., \& Oddy, W. H. (2009). A good-quality breakfast is associated with better mental health in adolescence. Public Health Nutrition, 12(2), 249-258. http://dx.doi.org/10.1017/S1368980008003935

Oddy, W. H., Robinson, M., Ambrosini, G. L., O’Sullivan, T. A., de Klerk, N. H., Beilin, L. J., ... Stanley, F. J. (2009). The association between dietary patterns and mental health in early adolescence. Preventive Medicine, 49, 39-44. http://dx.doi.org/10.1016/j.ypmed.2009.05.009 
Oellingrath, I. M., Svendsen, M. V., \& Hestetun, I. (2013). Eating patterns and mental health problems in early adolescence-A cross-sectional study of 12-13-year-old Norwegian schoolchildren. Public Health Nutrition. http://dx.doi.org/10.1017/S1368980013002747

Ortega, F. B., Ruiz, J. R., Castillo, M. J., \& Sjostrom, M. P. (2008). Physical fitness in childhood and adolescence: A powerful marker of health. International Journal of Obesity, 32(1), 1-11.

Pan, X., Zhang, C., \& Shi, Z. (2011). Soft drink and sweet food consumption and suicidal behaviours among Chinese adolescents. Acta Paediatrica, 100, 215-222. http://dx.doi.org/10.1111/j.1651-2227.2011.02369.x

Patterson, J. M. (2002). Understanding family resilience. Journal of Clinical Psychology, 58, 233-246. http://dx.doi.org/10.1002/jclp.10019

Pettit, G. S., Bates, J. E., Dodge, K. A., \& Meece, D. W. (1999). The impact of after-school peer contact on early adolescent externalizing problems is moderated by parental monitoring, perceived neighborhood safety, and prior adjustment. Child Development, 70(3), 768-778.

Primack, B. A., Swanier, B., Georgiopoulos, A. M., Land, S. R., \& Fine, M. J. (2009). Association between media use in adolescence and depression in young adulthood. Archieve General Psychiatry, 66(2), 181-188. http://dx.doi.org/10.1001/archgenpsychiatry.2008.532

Rak, C. F., \& Patterson, L. E. (1996). Promoting resilience in at-risk children. Journal of Counseling \& Development, 74, 368-373. http://dx.doi.org/10.1002/j.1556-6676.1996.tb01881.x

Richards, J., Foster, C., Townsend, N., \& Bauman, A. (2014). Physical fitness and mental health impact of a sport-for-development intervention in a post-conflict setting: randomised controlled trial nested within an observational study of adolescents in Gulu, Uganda. BMC Public Health, 14(619). http://dx.doi.org/10.1186/1471-2458-14-619

Rutter, M. (1985). Resilience in the face of adversity: Protective factors and resistance to psychiatric disorder. British Journal of Psychiatry, 147, 598-611. http://dx.doi.org/10.1192/bjp.147.6.598

Rutter, M. (1987). Psychosocial resilience and protective mechanisms. American Journal of Orthopsychiatry, 57(3), 316-331. http://dx.doi.org/10.1111/j.1939-0025.1987.tb03541.x

Rutter, M. (2006). Implications of resilience concepts for scientific understanding. Annals of New York Academy of Sciences, 1094(1), 1-12. http://dx.doi.org/10.1196/annals.1376.002

Sarchiapone, M., Mandelli, L., Carli, V., Iosue, M., Wasserman, C., Hadlaczky, G., ... Wasserman, D. (2014). Hours of sleep in adolescents and its association with anxiety, emotional concerns, and suicidal ideation. Sleep Medicine, 15(2), 248-254.

Sharkey, J. D., You, S., \& Schnoebelen, K. (2008). Relations among school assets, individual resilience, and student engagement for youth grouped by level of family functioning. Psychology, 45, 402. http://dx.doi.org/10.1002/pits.20305

Skrove, M., Romundsta, P., \& Indredavik, M. S. (2013). Resilience, lifestyle and symptoms of anxiety and depression in adolescence: The Young-HUNT study. Social Psychiatry and Psychiatric Epidemiology, 48(3), 407-416. http://dx.doi.org/10.1007/s00127-012-0561-2.

Stalsberg, R., \& Pedersen, A. V. (2010). Effects of socioeconomic status on the physical activity in adolescents: A systematic review of the evidence. Scandinavian Journal of Medicine \& Science in Sports, 20, 368-383. http://dx.doi.org/10.1111/j.1600-0838.2009.01047.x

Sterne, J. A. C., White, I. R., Carlin, J. B., Spratt, M., Royston, P., Kenward, M. G., ... Carpenter, J. C. (2009). Multiple imputation for missing data in epidemiological and clinical research: Potential and pitfalls. British Medical Journal, 338, 1-17. http://dx.doi.org/10.1136/bmj.b2393

Strohle, A. (2009). Physical activity, exercise, depression and anxiety disorders. Journal of Neural Transmission, 116(6), 777-784. http://dx.doi.org/10.1007/s00702-008-0092-x.

Takaoka, Y., \& Kawakami, N. (2013). Fruit and vegetable consumption in adolescence and health in early adulthood: A longitudinal analysis of the Statistics Canada's National Population Health Survey. BMC Public Health, 13(1206). http://dx.doi.org/10.1186/1471-2458-13-1206 
Theron, L., Liebenberg, L., \& Malindi, M. (2014). When schooling experiences are respectful of children's rights: A pathway to resilience. School Psychology International, 35(3), 253-265. http://dx.doi.org/1177/0142723713503254

Turner, M. G., Exum, M. L., Brame, R., \& Holt, T. J. (2013). Bullying victimization and adolescent mental health: General and typological effects across sex. Journal of Criminal Justice, 41(1), 53-59. http://dx.doi.org/10.1016/j.jcrimjus.2012.12.005

Ungar, M. (2001). The social construction of resilience among "problem" youth in out-of-home placement: A study of health-enhancing deviance. Child \& Youth Care Forum, 30(3), 137-154.

Ungar, M. (2010). What is resilience across cultures and contexts? Advances to the theory of positive development among individuals and families under stress. Journal of Family Psychotherapy, 21(1), 1-16. http://dx.doi.org/10.1080/08975351003618494

Ungar, M. (2012). Social ecologies and their contribution to resilience. In M. Ungar (Ed.), The social ecology of resilience: A handbook of theory and practice (pp. 13-32). New York: Springer.

Ungar, M., Russell, P., \& Connelly, G. (2014). School-based interventions to enhance the resilience of students. Journal of Educational and Developmental Psychology, 4(1), 66-83. http://dx.doi.org/10.5539/jedp.v4nlp66

Walsh, F. (2002). A family resilience framework: Innovative practice application. Family Relations, 51, 130-137. http://dx.doi.org/10.1111/j.1741-3729.2002.00130.x

Weng, T.-T., Hao, J.-H., Qian, Q.-W., Cao, H., Fu, J.-L., Sun, Y., ... Tao, F.-B. (2011). Is there any relationship between dietary patterns and depression and anxiety in Chinese adolescents? Public Health Nutrition, 15(4), 673-682. http://dx.doi.org/10.1017/S1368980011003077

Werner, E., \& Smith, R. (1982). Vulnerable but invincible: A study of resilient children. New York: McGraw-Hill.

Williams, P. G., Holmbeck, G. N., \& Greenley, R. N. (2002). Adolescent health psychology. Journal of Consulting and Clinical Psychology, 70(3), 828-842. http://dx.doi.org/10.1037//0022-006X.70.3.828

Winders, S.-J. (2014). From extraordinary invulnerability to ordinary magic: A literature review of resilience. Journal of European Psychology Students, 5(1), 3-9. http://dx.doi.org/10.5334/jeps.bk

Windle, G. (2011). What is resilience? A review and concept analysis. Reviews in Clinical Gerontology, 21(2), 152-169. http://dx.doi.org/10.1017/S0959259810000420

Wu, Q., Palinkas, L. A., \& He, X. (2010). An ecological examination of social capital effects on the academic achievement of Chinese migrant children. British Journal of Social Work, 40, 2578-2597. http://dx.doi.org/10.1093/bjsw/bcq051

Yousafzai, A. K., Rasheed, M. A., \& Bhutta, Z. A. (2013). Annual research review: Improved nutrition-A pathway to resilience. The Journal of Child Psychology and Psychiatry, 54(4), 367-377. http://dx.doi.org/10.1111/jcpp.12019

Zamani, E., Chashmi, M., \& Hedayati, N. (2009). Effect of addiction to computer games on physical and mental health of female and male students of guidance school in city of Isfahan. Addiction \& Health, 1(2), 98-104.

Zimmerman, M. A. (2013). Resilience theory: A strengths-based approach to research and practice for adolescent health. Health Education \& Behavior, 40(4), 381-383. http://dx.doi.org/10.1177/1090198113493782

\section{Copyrights}

Copyright for this article is retained by the author, with first publication rights granted to the journal.

This is an open-access article distributed under the terms and conditions of the Creative Commons Attribution license (http://creativecommons.org/licenses/by/3.0/). 